\title{
Toxicity of pentachlorophenol to native aquatic species in the Yangtze River
}

\author{
Xiaowei Jin • Jinmiao Zha • Yiping Xu • John P. Giesy • \\ Zijian Wang
}

Received: 14 June 2011 / Accepted: 17 August 2011 /Published online: 1 September 2011

(C) Springer-Verlag 2011

\begin{abstract}
Introduction While the literature is replete with studies of the toxic potency of pentachlorophenol (PCP), site-specific criteria for native aquatic species that can be used in ecological risk assessments has been lacking and application of toxicity information for non-native species is controversial.

Materials and methods In the present study, acute and chronic toxicities of PCP to six aquatic species native to the Yangtze River were determined. The $\mathrm{HC}_{5}$ and $\mathrm{HC}_{50}$
\end{abstract}

Responsible editor: Thomas Braunbeck

Electronic supplementary material The online version of this article (doi:10.1007/s11356-011-0594-1) contains supplementary material, which is available to authorized users.

X. Jin $\cdot$ J. Zha $\cdot$ Y. Xu $\cdot$ Z. Wang $(\bowtie)$

State Key Laboratory of Environmental Aquatic Chemistry,

Research Center for Eco-Environmental Sciences,

Chinese Academy of Sciences,

P.O. Box 2871, Shuangqing Road 18, Haidian District,

Beijing 100085, China

e-mail: wangzj@rcees.ac.cn

J. P. Giesy

Department of Veterinary Biomedical Sciences and Toxicology

Centre, University of Saskatchewan,

Saskatoon, Saskatchewan, Canada

\section{J. P. Giesy}

Department of Zoology, and Center for Integrative Toxicology,

Michigan State University,

East Lansing, MI, USA

J. P. Giesy

Zoology Department, College of Science, King Saud University,

P.O. Box 2455, Riyadh 11451, Saudi Arabia

\section{J. P. Giesy}

Department of Biology and Chemistry,

City University of Hong Kong,

Kowloon, Hong Kong (hazardous concentration for $5 \%$ and $50 \%$ of species) were derived from dose-response curves for these native aquatic species and were then compared with those derived for non-native species.

Results The acute toxicity values for the native species ranged from $8.8 \times 10^{-2} \mathrm{mg} \mathrm{l}^{-1}$ (Plagiognathops microlepis) to $1.1 \mathrm{mg}^{-1}$ (Soirodela polyrhiza), while chronic toxicity values based on no observed effect concentrations (NOECs) ranged from $0.01 \mathrm{mg} \mathrm{l}^{-1}$ (Macrobrachium superbum) to $0.25 \mathrm{mg} \mathrm{l}^{-1}$ (Soirodela polyrhiza). Native aquatic benthos was more sensitive to acute PCP exposure than non-native species. There was no significant difference in NOECs derived from native fish species and those based on nonnative fish species. The median acute $\mathrm{HC}_{5}$ and $\mathrm{HC}_{50}$ derived from the toxicity data of native taxa were both less than those derived from non-native taxa. There was no significant difference between chronic $\mathrm{HC}_{5} \mathrm{~s}$ derived from the two sets of taxa. However, the median chronic $\mathrm{HC}_{50}$ derived from native taxa was less than that derived from non-native taxa.

Conclusion The study upon which we report here provides site-specific toxicity information developed for native species which can be used for the protection of local aquatic life from a common contaminant, PCP.

Keywords China $\cdot$ Acute $\cdot$ Chronic $\cdot$ Native $\cdot$ Species sensitivity distribution . Water quality criteria

\section{Introduction}

Chlorophenols are organic compounds that have been used since the late 18th century and are frequently detected in effluents of industries and in the natural water environment (Gao et al. 2008; Stangroom et al. 1998). Among them, 
pentachlorophenol (PCP) has been used as a general biocide to control termites and protect wood from fungal-rot and woodboring insects (Thakur et al. 2001). In China, PCP and its salts were used principally as a molluskicide to control snail-borne schistosomiasis as well as a wood preservative. It was also used extensively in aquaculture as a pond-cleaning reagent to control Ampullaria gigas, a winkle mollusk introduced into China in the 1980s. Although, use of PCP as a pesticide in China was banned 1997, PCP is still utilized as a wood preservative (Zheng et al. 2000). Because of its toxicity to aquatic life, recalcitrance to aerobic biodegradation and potential bioaccumulation, PCP has been recognized as a priority pollutant in the United States as well as in China (USEPA 1991; Xia et al. 2004). PCP is reported to be an endocrine disruptor (Orton et al. 2009; Zha et al. 2006), and is also a recognized class $2 \mathrm{~B}$ carcinogen by the International Agency for Research on Cancer (IARC) (Ge et al. 2007).

While data on the toxicity of PCP have been widely reported (Adema and Vink 1981; Belgers et al. 2009; Besser et al. 2005; Dwyer et al. 2005), information on the toxicity of PCP to native species in that can be used in sitespecific risk assessments and establishing water quality guidelines or criteria (WQC) in China has been lacking. The potential use of toxicity data for non-native species to develop local criteria is controversial due to uncertainty whether criteria based on species from one geographical region provide appropriate protection for species in a different region (Davies et al. 1994). This was primarily due to a paucity of toxicity data applicable for local species in China. Guidelines developed by the USEPA for development of freshwater and marine WQC should be based on wildlife species distributed in North America (USEPA 1985). In Australia, species sensitivity distributions (SSDs) are used to estimate the concentration that would be protective of $95 \%$ of species (PC95) are used to derive WQC for toxicants based on Australian toxicity information for all species or site-specific species (ANZECC \& ARMCANZ 2000; Hose and Van den Brink 2004). It has been suggested that it would be most appropriate to develop site-specific WQC for China based on indigenous species (Yin et al. 2003a, b).

The SSD concept is sometimes used to provide a probabilistic ecological risk assessment and to estimate chemical concentrations protective of most species in the environment (Caldwell et al. 2008; Duboudin et al. 2004; Dyer et al. 2008; Giddings et al. 2009; Grist et al. 2006; Jagoe and Newman 1997; Roessink et al. 2006; Simpson 2005). A point estimate known as the $\mathrm{HC}_{x}$ (hazardous concentration for $x \%$ of species) is calculated. This is a concentration that will result in a specified magnitude of effect for no more than $x \%$ of species, such as the Lowest Observable Effect Concentration (LOEC), No Observable Effect Concentration (NOEC) or the median lethal concen- trations $\left(\mathrm{LC}_{50}\right.$.) SSDs are constructed by fitting cumulative probability distributions that plot the concentration associated with eliciting a particular response from a particular species as a function of rank-assigned centile (Giesy et al. 1999; Solomon et al. 2000; Vanstraalen and Denneman 1989; Wheeler et al. 2002)

In the study upon which we report here, acute and chronic toxicity of PCP to six native species native to the Yangtze River, including three fishes, two species of invertebrate and one aquatic macrophyte were determined. SSDs were developed and $\mathrm{HC}_{5}$ and $\mathrm{HC}_{50}$ values determined for a species reported in the literature and for the non-native taxa. The objectives of the study were to: (1) supplement the data base for toxicity of PCP, especially for species endemic to China; (2) compare the tolerance of native species and nonnative species to $\mathrm{PCP}$.

\section{Materials and methods}

\subsection{Test species and conditions}

Six species endemic to China, three fishes (Black carp; Mylopharyngodon piceus, Smallscale yellowfin; Plagiognathops microlepis and Culter alburnus Erythroculter ilishaeformis); one crustacean (Freshwater shrimp Macrobrachium superbum); one mollusk (Asian clam Corbicula fluminea) and one hydrophyte (Greater duckweed Soirodela polyrhiza) were selected primarily based on their wide distributions, economic significance and adaptability to laboratory conditions. These test species were provided by the Huazhong Agricultural University (Wuhan, China), and they were acclimatized to test conditions $\left(24 \pm 1^{\circ} \mathrm{C}, \mathrm{pH} 7.24 \pm 0.16\right)$ for more than 2 weeks prior to the experiments.

The minimum average dissolved oxygen concentration for all the test species was maintained at greater than $80 \%$ saturation. The $\mathrm{pH}$ averaged 7.65 . Conductivity $(\mathrm{mmhos} / \mathrm{cm})$ and hardness (as mg $\mathrm{l}^{-1} \mathrm{CaCO}_{3}$ ) averaged 512 and 100, total organic carbon (TOC) content $=0.017 \mathrm{mg} \mathrm{l}^{-1}$ during the freshwater tests. Strip chart records of temperature showed that the average temperature of $24 \pm 1^{\circ} \mathrm{C}$ was maintained for all tests. Analytical grade PCP $\left(\mathrm{HOC}_{6} \mathrm{Cl}_{5}\right)(\mathrm{CAS} \mathrm{RN} 87-86-5)$ of $99.0 \%$ purity was purchased from ACROS Organics (New Jersey, USA). Dissolved oxygen, conductivity, temperature, $\mathrm{pH}$, and salinity were measured with a multi-parameter water quality meter (YSI Model 85 meter; Yellow Springs, OH).

\subsection{Acute toxicity tests}

Acute exposure of fishes, macroinvertebrates and hydrophytes, followed the international standard guidelines (ASTM 1993; OECD 2002; USEPA 1993). Static-renewal acute exposures to PCP were conducted in a temperature controlled room. Test 
solutions were maintained by renewal of $90 \%$ of the water in the test chambers every $24 \mathrm{~h}$. There were five treatments (nominal concentration) of test chemical plus a control and three replicates of each. Test concentrations were chosen based upon the results of preliminary range-finding tests (data not shown).

Juveniles of M. piceus $(17.65 \pm 0.40 \mathrm{~mm}, 3.80 \pm 0.22 \times$ $\left.10^{-2} \mathrm{~g}\right)$, P. microlepis $\left(16.40 \pm 0.37 \mathrm{~mm}, 2.67 \pm 0.19 \times 10^{-2} \mathrm{~g}\right)$ and E. ilishaeformis $\left(23.59 \pm 0.29 \mathrm{~mm}, 5.50 \pm 0.20 \times 10^{-2} \mathrm{~g}\right)$ and $C$. fluminea with a mean shell length of $20.80 \pm$ $0.20 \mathrm{~mm}$, a mean shell height of $19.40 \pm 0.20 \mathrm{~mm}$ and mean body weight of $3.66 \pm 0.40 \mathrm{~g}$ wet wt. were tested in glass beakers containing $1,000 \mathrm{ml}$ test solution and ten test organisms. M. superbum ( $39.63 \pm 0.47 \mathrm{~mm}, 0.87 \pm 0.08 \mathrm{~g})$ was tested in glass container containing $4,000 \mathrm{ml}$ test solution and ten test organisms. Nominal concentrations used in these studies were $0,0.05,0.10,0.15,0.20$ and $0.25 \mathrm{mg}^{-1}$ PCP for both M. piceus and E. ilishaeformis, 0 , 0.05, 0.08, 0.10, 0.12, $0.15 \mathrm{mg} \mathrm{l}^{-1}$ for P. microlepis, 0, 0.10, $0.20,0.40,0.60,0.80 \mathrm{mg}^{-1}$ and $0,0.04,0.08,0.16,0.32$, $0.64 \mathrm{mg}^{-1}$ PCP for C. fluminea and M. superbum, respectively. During the exposure, beakers were kept in an incubator at $24 \pm 1{ }^{\circ} \mathrm{C}$ with $16 \mathrm{~L}: 8 \mathrm{D}$ photoperiod. Test organisms were not fed during the exposure period. Mortality and abnormal behavior were monitored daily and dead organisms were removed immediately.

$S$. polyrhiza was cultured in the laboratory in halfstrength Hoagland's medium (Yuan and Yang 1983) under $2,000 \mathrm{~lx}$ and $24 \pm 1{ }^{\circ} \mathrm{C}$. The $\mathrm{IC}_{50}$ (median inhibitory concentration) tests were conducted in $90-\mathrm{mm}$ glass crystallizing dishes. Each container contained about $200 \mathrm{ml}$ test medium and ten fronds of S. polyrihiza. The nominal concentrations used in the definitive studies were $0,0.10,0.25,0.50,1.00$ and $2.00 \mathrm{mg} \mathrm{l}^{-1}$ PCP. Plants were maintained at $24 \pm 1^{\circ} \mathrm{C}$ for $24 \mathrm{~h}$ light. The number of fronds in each beaker was counted daily. No mortality or other adverse effects were observed in the control.

\subsection{Sub-chronic toxicity tests}

Sub-chronic continuous exposures of PCP to six native species were conducted using daily replaced static-renewal diluters. Test conditions and solution renewal procedures were the same as above. Six nominal concentrations (five treatments plus a control) of PCP were used as experimental treatments, each replicated three times. Test concentrations were selected based on the results of the acute toxicity tests. Water quality parameters were measured every 2 days.

Chronic toxicity of PCP to M. superbum and C. fluminea was determined in 21-day exposures conducted in glass containers containing 4,000 or $1,000 \mathrm{ml}$ test solution, respectively. Test organisms were fed daily with a solution of microalgae concentrates prepared from instant algae shellfish diet and Nannochloropsis concentrate according to standard guidelines for conducting chronic tests with macroinvertebrates (ASTM 1993). At the end of test, the 21-day NOEC and LOEC based on survival rate and behavior of test organisms.

Sub-chronic inhibition of growth of M. piceus, P. microlepis and E. ilishaeformis was determined using 28-day exposures of early life stages in glass containers containing $1,000 \mathrm{ml}$ test solution. During the exposure, juvenile fishes were fed a commercial granulated food (Tetra, Germany) at a rate of $0.1 \%$ body weight, once per day and newly hatched brine shrimp (Artemia sp.) nauplii twice a day. At the end of the test, length and weight of all tested fish were measured and survival determined. The specific growth rate (SGR) of fry was used because it is less dependent on the initial size of the fish and on the time between measurements than the other endpoint such as relative growth rate (RGR) (Mallett et al. 1997). The SGR was calculated as ((ln(final mass) $-\ln$ (initial mass) $\times 100)$ /days of exposure (Crossland 1985). No mortality was observed in the control.

Sub-chronic toxicity of PCP to $S$. polyrihiza was 10-day exposures, which were conducted in $90-\mathrm{mm}$ glass crystallizing dish with $200 \mathrm{ml}$ test medium. At the end of the test, chlorophyll was measured using 7550 ultraviolet and visible spectrophotometer (Zhang and Jin 1997), from which NOEC and LOEC were derived.

\subsection{Chemical analysis}

During the acute and chronic toxicity exposures actual concentrations of PCP were determined in randomly collected samples of the control, and low, medium, and high dosage concentrations. Triplicate samples were taken from one tank of each concentration. Samples were spiked with surrogate standard (Biphenol A-d16), adjusted to $\mathrm{pH}<$ 2 with $6 \mu \mathrm{M}$ hydrochloride buffer and extracted with SPE using $\mathrm{C} 18$ cartridge. Cartridges were eluted with $10 \mathrm{ml}$ dichloromethane (DCM). All extracts were evaporated under a gentle stream of nitrogen. Derivatization was performed to convert phenols to less polar derivatives, which were more amenable to quantification by use of gas chromatography. The dried residues were derivatized by BSTFA with $1 \%$ TMCS, which were heated in a heating block at $60^{\circ} \mathrm{C}$ for $2 \mathrm{~h}$. Samples were maintained at $4^{\circ} \mathrm{C}$ in brown polypropylene bottles in the dark until analysis.

PCP was quantified by use of an Agilent 6890 gas chromatograph equipped with Agilent MSD 5975 mass spectrometer. Chromatography was performed by use of a $30 \mathrm{~m}, 0.25 \mathrm{~mm}$ HP-5 capillary column. Gas chromatography (GC) oven temperatures were programmed to start at $40^{\circ} \mathrm{C}$ and increase to $300^{\circ} \mathrm{C}$ via a ramp of $10^{\circ} \mathrm{C} \mathrm{min}^{-1}$ and maintained at $40^{\circ} \mathrm{C}$ for $2 \mathrm{~min}$ and at $300^{\circ} \mathrm{C}$ for $15 \mathrm{~min}$. Then constant pressure model was used in the whole analysis 
process. The inlet and MS transfer line temperatures were maintained at $250^{\circ} \mathrm{C}$, and the ion source temperature was $300^{\circ} \mathrm{C}$. Sample injection $(1 \mu \mathrm{l})$ was in splitless mode. Mass spectra (MS) were collected in full-scan mode from $\mathrm{m} / \mathrm{z} 50$ 700 for qualitative analysis, but selected ion monitoring (SIM) mode was used for quantification. The data of GC-MS were analyzed by the techniques of RTL and DRS (software provided by Agilent).

Measured PCP concentrations in the treated fish species collected during experiments ranged from $89.2 \%$ to $106.4 \%$ of nominal concentrations (mean 96.7\%, $n=72$ ). PCP was not detected in control medium or blanks. Therefore, all subsequent acute and chronic toxicity results were expressed on nominal concentrations of PCP.

\subsection{Statistical analysis}

The measurement endpoint during acute exposures was lethality, except for $S$. polyrihiza for which the endpoint was growth. The $\mathrm{LC}_{50}$ and $95 \%$ confidence interval (CI) of the $\mathrm{LC}_{50} \mathrm{~s}$ for each test were calculated using the Probit Program Version 1.5 (USEPA 1990). Concentrations associated with $50 \%$ inhibition of growth $\left(\mathrm{IC}_{50}\right)$ for $S$. polyrihiza were determined using standard methods recommended by the Organization for Economic Co-operation and Development (OECD 2002). Results of chronic tests were analyzed using SPSS Version 17 software. After data were checked for homogeneity of variance by use of Levene's test, one-way analysis of variance (ANOVA) followed by Dunnett's multiple comparison tests to determine which concentration produced responses that were different from the control. The level of statistical significances applied was $p \leq 0.05$. The NOEC was defined as the greatest concentration that did not result in a significant effect compared with the control. The LOEC was defined as the least concentration that did result in a significant effect compared with the control, The maximum allowable toxicant concentration (MATC) was equal to the geometric average of NOEC and LOEC (USEPA 1985).

\subsection{Data collection and SSD generation}

Additional acute and chronic toxicity data for PCP were collected from existing toxicity databases (e.g., ECOTOX Database, http://cfpub.epa.gov/ecotox/), published in the literature, and government document follow the principles of accuracy, relevance and reliability (Caldwell et al. 2008; Klimisch et al. 1997). For acute toxicity data, selected measurement endpoints were median lethal concentration $\left(\mathrm{LC}_{50}\right)$ or median effect concentration $\left(\mathrm{EC}_{50}\right)$ based on immobility for animals and biomass or growth for plants. For chronic toxicity data, NOECs were calculated from the available literature. When a NOEC was not available, MATC or LOEC or $\mathrm{EC}_{\mathrm{x}}$ was used. If more than one set of data for the same species was available, toxicity values for the most sensitive end point were chosen. In the case of multiple data on the same end point and species, the geometric mean was used. Toxicity data were considered "native" if test organisms were endemic to natural ecosystems of China and if tests were conducted under conditions appropriate for Chinese environmental conditions. Information on toxicity of PCP to local species, including the six native species for which information was collected during this study, and other data on native species from the literature, were combined and compared with the data for non-native taxa.

Data from toxicity tests are sometimes log-normally distributed and the log-logistic distribution best fit toxicity data (Wheeler et al. 2002). However, several other techniques including parametric (e.g., Weibull distributions) and nonparametric methods (e.g., use of statistical software packages such as "EasyFit") can be used to construct a SSDs that accurately describe the cumulative frequency function. Both statistical tests, such as the Kolmogorov-Smirnov or Anderson-Darling tests and graphical techniques such as Q-Q plots, and various goodness-of-fit techniques can be used to select the most appropriate distribution function for a data set. To select the most appropriate distribution for a given data set, goodness-of-fit statistics (software EasyFit, version 5.3) are used. Preference was given to the AndersenDarling (A-D) test because it places more emphasis on tail values (Caldwell et al. 2008). A critical $p$ value (statistical significance level) of 0.05 was used to determine goodness of fit. The lower (5\%), median (50\%), and upper (95\%) CIs, the $\mathrm{HC}_{5}$ and $\mathrm{HC}_{50}$ were estimated by use of the BurrliOZ program (CSIRO v I.O.13; Perth, Australia) (Campbell et al. 2000). BurrliOZ fits the Burr type III distribution (Shao 2000), which is a flexible three-parameter distribution that provides approximations of commonly used distributions such as the log-normal, log-logistic, and Weibull (Hose and Van den Brink 2004). The BurrliOZ software calculates CIs for $\mathrm{HC}_{5}$ and $\mathrm{HC}_{50}$ values using a bootstrap technique (Campbell et al. 2000). As a result, CIs can vary among iterations. Therefore, each interval was estimated 10 times using 1,000 permutations. The geometric mean of those ten calculations was used as the best estimate of the lower and upper boundaries of the $\mathrm{HC}_{5}$ and $\mathrm{HC}_{50}$ (Hose and Van den Brink 2004). Sensitivity distributions were compared using the two-sample Kolmogorov-Smirnov test using the SPSS Version 17 software.

\section{Results}

\subsection{Acute toxicity}

While PCP was toxic to the six native species tested, based on acute lethality, represented by the $\mathrm{LC}_{50}$ and $95 \% \mathrm{CI}, P$. 
microlepis was the most sensitive of the three fishes with an $\mathrm{LC}_{50}$ of $0.09 \mathrm{mg} \mathrm{PCP} \mathrm{l}^{-1}(0.08-0.10)$, followed by M. piceus and $E$. ilishaeformis with 96-h $\mathrm{LC}_{50}$ values of $0.10(0.08$ $0.11)$ and $0.13(0.12-0.14) \mathrm{mg}$ PCP $\mathrm{l}^{-1}$, respectively (Table 1). The two invertebrates were less sensitive with 96-h $\mathrm{LC}_{50}$ values for $M$. superbum and $C$. fluminea were $0.14(0.10-0.19)$ and $0.23(0.18-0.27) \mathrm{mg} \mathrm{PCP} \mathrm{l}^{-1}$, respectively. Toxicity of PCP was inversely proportional to duration of exposure.

Growth of the macrophyte $S$. polyrhiza was significantly less when exposed to PCP for $96 \mathrm{~h}$, and was dosedependent (Fig. 1). The 96-h $\mathrm{IC}_{50}$ of S. polyrhiza was $1.12 \mathrm{mg}$ PCP $1^{-1}$.

\subsection{Sub-chronic toxicity}

The species tested exhibited differential tolerances to PCP during 21-day chronic exposures (Table 2). Of the two invertebrates, $M$. superbum was more sensitive to PCP than $C$. fluminea. The NOEC of the two invertebrates were 0.01 and $0.06 \mathrm{mg} \mathrm{PCP} 1^{-1}$; and LOECs were 0.015 and $0.08 \mathrm{mg}$ PCP $1^{-1}$, respectively. The MATC for the invertebrates were 0.012 and $0.07 \mathrm{mg} \mathrm{PCP}^{-1}$, respectively. While all individuals of early life stages of M. piceus, P. microlepis and E. ilishaeformis survived until the end of the 28-day tests their growth rates were SGRs were less in the PCPtreated individuals. The SGRs of unexposed individuals of the three species tested were $2.84 \%, 2.86 \%$ and $4.70 \%$ per day, respectively. Growth of M. piceus, was significantly inhibited at concentrations greater than $0.02 \mathrm{mg} \mathrm{PCP}^{-1}$ $(p<0.01$; ANOVA). SGRs of juvenile $P$. microlepis, were significantly less than that of the controls when exposed to concentrations of PCP of $0.02 \mathrm{mg} \mathrm{l}^{-1}$ or greater. The threshold for inhibition of specific growth of E. ilishaeformis, was $0.03 \mathrm{mg} \mathrm{PCP} \mathrm{l}^{-1}$. NOEC values based on growth inhibition

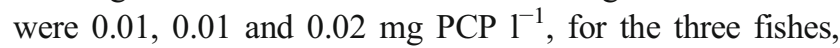

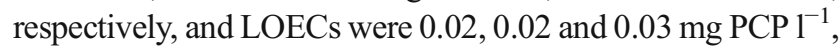
respectively. The MATCs were $0.014,0.014$ and $0.025 \mathrm{mg}$ PCP $1^{-1}$ for M. piceus, P. microlepis and E. ilishaeformis, respectively.

The results of 10-day toxicity tests with S. polyrihiza showed that the chlorophyll content decreased gradually with increasing PCP exposure concentrations (Fig. 2). The chlorophyll content reduced by $96.7 \%$, relative to that of the control at $0.10 \mathrm{mg} \mathrm{l}^{-1}$, and to $66.5 \%$ at $2.00 \mathrm{mg} \mathrm{l}^{-1}$. The calculated NOEC, LOEC and MATC were $0.25,0.50$ and $0.35 \mathrm{mg}^{-1}$, respectively.

3.3 Comparison of $\mathrm{HCx}$ derived from native and non-native taxa

A total of 12 acute toxicity data based on the native species were collected, including four fishes, five invertebrates, one planktonic alga and two hydrophytes. Sixty acute $\mathrm{LC}_{50}$ $\left(\mathrm{EC}_{50}\right)$ values were found from literature that based on nonnative taxa, among them 26 data points were from fish taxa,
Table 1 Acute toxicity of PCP to five aquatic animals endemic to China

\begin{tabular}{|c|c|c|c|c|}
\hline Species (common name) & Exposure time (h) & $\mathrm{LC}_{50}\left(\mathrm{mg} \mathrm{l}^{-1}\right)$ & $95 \% \mathrm{CI}$ & $R^{2}$ \\
\hline \multirow[t]{4}{*}{ C. fluminca (Asian clam) } & 24 & 0.98 & $0.62-15.11$ & 0.81 \\
\hline & 48 & 0.52 & $0.44-0.68$ & 0.86 \\
\hline & 72 & 0.23 & $0.18-0.27$ & 0.89 \\
\hline & 96 & 0.23 & $0.18-0.27$ & 0.87 \\
\hline \multirow[t]{4}{*}{ M. superbum (Freshwater shrimp) } & 24 & 0.98 & $0.45-14.30$ & 0.83 \\
\hline & 48 & 0.56 & $0.32-2.31$ & 0.83 \\
\hline & 72 & 0.27 & $0.16-0.69$ & 0.94 \\
\hline & 96 & 0.14 & $0.10-0.19$ & 0.82 \\
\hline \multirow[t]{4}{*}{ M. piceus (Black carp) } & 24 & 0.16 & $0.15-0.18$ & 0.91 \\
\hline & 48 & 0.13 & $0.12-0.14$ & 0.93 \\
\hline & 72 & 0.11 & $0.10-0.12$ & 0.99 \\
\hline & 96 & $9.5 \times 10^{-2}$ & $0.08-0.11$ & 0.98 \\
\hline \multirow[t]{4}{*}{ P. microlepis (Smallscale yellowfin) } & 24 & 0.14 & $0.13-0.17$ & 0.90 \\
\hline & 48 & 0.12 & $0.11-0.13$ & 0.95 \\
\hline & 72 & 0.10 & $0.09-0.11$ & 0.96 \\
\hline & 96 & 0.09 & $0.08-0.10$ & 0.98 \\
\hline \multirow[t]{4}{*}{ E. ilishaeformis (Culter alburnus) } & 24 & 0.18 & $0.17-0.19$ & 0.93 \\
\hline & 48 & 0.15 & $0.14-0.17$ & 0.97 \\
\hline & 72 & 0.14 & $0.13-0.15$ & 0.94 \\
\hline & 96 & 0.13 & $0.12-0.14$ & 0.95 \\
\hline
\end{tabular}




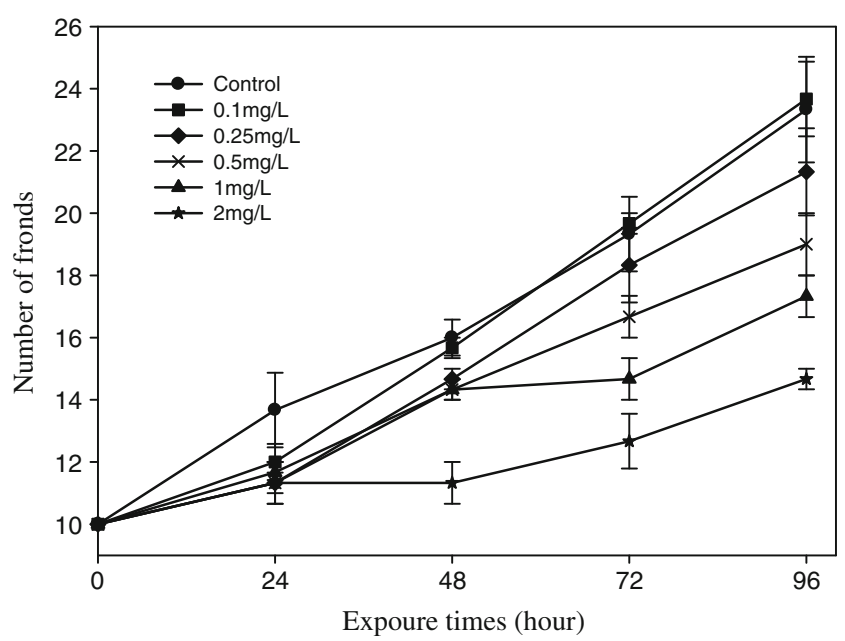

Fig. 1 Effect of 4 days exposure to PCP on Soirodela polyrhiza growth rate

30 from invertebrates, three from algae, and one hydrophyte, respectively (see Table S2). The calculated results are given in Table 3. A Burr Type III model was fitted to both acute native datasets and non-native datasets. From Table 3, the median $\mathrm{HC}_{5}$ and $\mathrm{HC}_{50}$ of acute data for native taxa were lower than those derived from non-native taxa. Compared to the SSD for non-native taxa, the SSD for native species was shifted considerably to the left (more sensitive) (Fig. 3a). The $\mathrm{HC}_{5}$ and $\mathrm{HC}_{50}$ values demonstrate that native species are more sensitive to acute exposure to PCP than non-native species. However, the sensitivity distribution for native species and for non-native species were not significantly different for acute toxicity data (Kolmogorov-Smirnov test: $\mathrm{ks}=1.16, n_{1}=12, n_{2}=60, p=0.13$ ). When toxicity data for native species were combined with those of non-native, a median $\mathrm{HC}_{5}$ of $0.052(0.038-0.070) \mathrm{mg}$ PCP $1^{-1}$ was calculated. This result was approximately equal to the median $\mathrm{HC}_{5}$ derived from toxicity data of non-native taxa separately. The differences of sensitivity distributions for native taxa and non-native taxa were also not statistically significant (Fig. 3a).

For chronic toxicity data, except for the six native species for which toxicity information was collected during this study, data for six additional native species for the same region were obtained from the literature. Nineteen chronic toxicity values were found for non-native taxa, of which seven values were for fish, seven for invertebrates, three for algae, and two for hydrophytes, respectively (see Table S3). A reciprocal Weibull model was fitted to both native and non-native chronic datasets. Results of the distributions are given in Table 3. The median $\mathrm{HC}_{5}$ of chronic data for native taxa and for non-native taxa were not significantly different (Fig. 3b). However, the median $\mathrm{HC}_{50}$ of chronic data for native taxa were lower than those derived from non-native taxa, but the differences of sensitivity distribution for native species and non-native species for chronic toxicity data were not statistically significant $\left(k s=0.55, n_{1}=12, n_{2}=19, p=\right.$ 0.93 ). When toxicity values for native species were combined with those of non-native, a median $\mathrm{HC}_{5}$ of 0.006 (0.003-0.009) mg PCP $1^{-1}$ was calculated. This result was approximately equal to the median $\mathrm{HC}_{5}$ derived from toxicity data of native or non-native taxa separately. The differences in sensitivity distributions for native taxa and non-native taxa were also not statistically significant (Fig. 3b).

\section{Discussion}

\subsection{Toxicity of PCP to native species}

The fact the three juvenile fishes exhibited similar sensitivities to PCP during both acute and chronic exposures may be due to the fact that these species are closely related, all being in the family Cyprinidae. The $96 \mathrm{~h} \mathrm{LC}_{50}$ values for PCP observed for the three fishes studied were similar to those reported for other cyprinid fishes (Nie et al. 2001; Zhou et al. 1995). There was no information in the literature on the toxicity of PCP to invertebrates endemic to China, to which results of the present study could be compared. The toxicity of PCP to aquatic plants previously has been reported for species endemic to China (Song and Huang 2005, 2007). The 8-day $\mathrm{IC}_{50}$ based on frond density was 8.08 and $2.37 \mathrm{mg}$ PCP $1^{-1}$ for Lemna polyrhiza and Lemna minor, respectively.
Table 2 Chronic toxicity of PCP to six aquatic species endemic to China

\begin{tabular}{llllll}
\hline Species (common name) & Times (days) & Measurement & \multicolumn{2}{l}{ Endpoint conc. (mg 1 ${ }^{-1}$ ) } \\
\cline { 4 - 6 } & & & NOAEC & LOAEC & MATC \\
\hline C. fluminca (Asian clam) & 21 & Survival & 0.06 & 0.08 & 0.07 \\
M. superbum (Freshwater shrimp) & 21 & Survival & 0.01 & $1.5 \times 10^{-2}$ & $1.2 \times 10^{-2}$ \\
M. piceus (Black carp) & 28 & Growth & 0.01 & 0.02 & $1.4 \times 10^{-2}$ \\
P. microlepis (Smallscale yellowfin) & 28 & Growth & 0.01 & 0.02 & $1.4 \times 10^{-2}$ \\
E. ilishaeformis (Culter alburnus) & 28 & Growth & 0.02 & 0.03 & $2.5 \times 10^{-2}$ \\
S. polyrhiza (Greater duckweed) & 10 & Chlorophyll & 0.25 & 0.50 & 0.35 \\
\hline
\end{tabular}




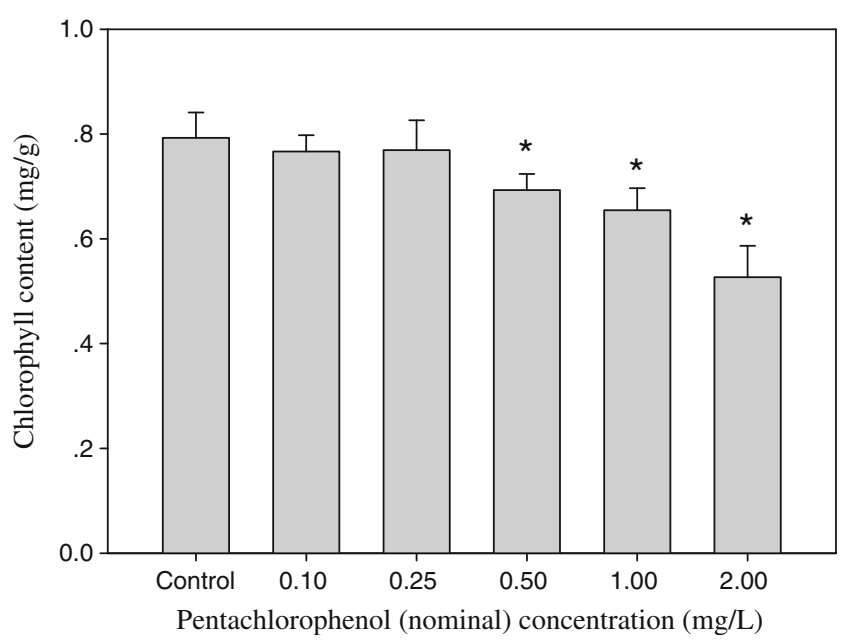

Fig. 2 Effect of 10 days exposure to PCP on chlorophyll content in Soirodela polyrhiza, Data are presented as means \pm standard deviation (SD). Significant differences from the values of the control at $* p<0.05$ and $* * p<0.01$, respectively

Thus, both $L$. polyrhiza and L. minor were less sensitive to PCP than was $S$. polyrhiza. Thresholds for effects, based on concentrations of chlorophyll in fronds of L. polyrhiza were reported to be 0.2 and $0.5 \mathrm{mg} \mathrm{PCP} 1^{-1}$ (Song and Huang 2007), which is similar to that observed for in the present study $\left(0.25\right.$ to $\left.0.5 \mathrm{mg} \mathrm{l}^{-1}\right)$.

\subsection{Comparison of tolerances of native and non-native taxa} to $\mathrm{PCP}$

The range of acute toxicities $\left(\mathrm{LC}_{50} \mathrm{~s}\right)$ of PCP to the three

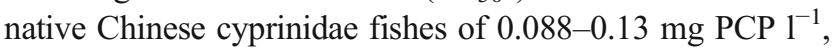
was slightly less than the range of values reported for cyprinidae $\left(0.19-0.26 \mathrm{mg} \mathrm{PCP}{ }^{-1}\right)$ and salmonidae $(0.17-$ $0.34 \mathrm{mg} \mathrm{PCP} \mathrm{l}^{-1}$ ) (Dwyer et al. 2005), Heteropneustes fossilis $\left(0.29 \mathrm{mg} \mathrm{l}^{-1}\right)$ and Colisa fasciata $\left(0.45 \mathrm{mg} \mathrm{PCP}^{-1}\right)$ (Verma et al. 1980). However, Verma et al. (1980) reported a $96 \mathrm{~h} \mathrm{LC}_{50}$ of $0.083 \mathrm{mg} \mathrm{PCP} \mathrm{L}{ }^{-1}$ for Notopterus notopterus. The reason for this difference was primarily due to the effect of $\mathrm{pH}$, since PCP is less toxic in alkaline waters than in acidic waters (USEPA 1986). This is due to protonation of the phenolic moiety making PCP less polar and facilitates accumulation across phosphor lipid membranes. Thus, it is probable that there are no differences in sensitivities between native fish and non-native fish exposed to PCP at the same $\mathrm{pH}$. The benthic crustaceans M. superbum studied here more sensitive than non-native species such as Chaetogammarus marinus, Penaeus duorarum and Ensis minor which have $96 \mathrm{~h} \mathrm{LC}_{50} \mathrm{~s}$ of 500, 5,600 and $344 \mu \mathrm{g}$ PCP $1^{-1}$, respectively (Adema and Vink 1981; USEPA 2002). The native bivalve studied here, $C$. fluminea, was approximately 5-fold more sensitive than the non-native, Sphaerium novaezelandiae (Hickey and Martin 1995). However, the native aquatic plant, $S$. polyrhiza was less sensitive than the non-native Thalassia testudinum with a 96-h $\mathrm{LC}_{50}$ of $740 \mathrm{PCP} \mu \mathrm{g} \mathrm{l}^{-1}$ (USEPA 2002).

In general the sensitivities of the native species tested in this study were similar to those reported in the literature. The chronic NOEC values for fishes ranging from 0.01 to $0.02 \mathrm{mg}$ $\mathrm{PCP}^{-1}$, based on inhibition of growth were slightly less than those of non-native species including, Erimonax monachus, Etheostoma fonticola and Oncorhynchus mykiss, whose NOECs were $0.035,0.015$ and $0.036 \mathrm{mg} \mathrm{PCP} 1^{-1}$, respectively (Besser et al. 2005). The tolerances of invertebrates including shrimp and benthic bivalve endemic species could not be compared to that of non-native species due to lack of information on non-native.

\subsection{Comparison between native and non-native taxa for species sensitivity distribution}

Since there has been little information on the toxicity of PCP to species endemic to China, the results of toxicity tests with species endemic to Europe or North America have been used in assessment of hazards posed by PCP in freshwater environments in China. The relevance of use species from one geographical region to assess the hazard posed to species in a different region has been questioned (Davies et al. 1994), and differences in the sensitivity of cold-water, temperate, and tropical fish species have been reported previously (Dyer et al. 1997). Based on results of this study, freshwater organisms endemic to China with

Table 3 Parameters of species sensitivity distributions for PCP based on native and non-native species toxicity data

\begin{tabular}{|c|c|c|c|c|c|}
\hline Toxicity data & $n$ & Mean $\left(\mathrm{mg} \mathrm{l}^{-1}\right)$ & Standard deviation & Median $\mathrm{HC}_{5}\left(\mathrm{mg} \mathrm{l}^{-1}\right)$ & Median $\mathrm{HC}_{50}\left(\mathrm{mg} \mathrm{l}^{-1}\right)$ \\
\hline Native acute data & 12 & 0.42 & 0.68 & $3.5 \times 10^{-2}\left(1.1 \times 10^{-2}-6.7 \times 10^{-2}\right)$ & $0.21(0.12-0.36)$ \\
\hline Non-native acute data & 60 & 0.62 & 1.0 & $5.7 \times 10^{-2}\left(3.9 \times 10^{-2}-7.8 \times 10^{-2}\right)$ & $0.32(0.26-0.41)$ \\
\hline All acute data & 72 & 0.59 & 0.98 & $5.2 \times 10^{-2}\left(3.8 \times 10^{-2}-7.0 \times 10^{-2}\right)$ & $0.30(0.24-0.37)$ \\
\hline Native chronic data & 12 & $3.4 \times 10^{-2}$ & $2.6 \times 10^{-2}$ & $0.60 \times 10^{-2}\left(0.20 \times 10^{-2}-1.1 \times 10^{-2}\right)$ & $3.2 \times 10^{-2}\left(1.9 \times 10^{-2}-5.3 \times 10^{-2}\right)$ \\
\hline Non-native chronic data & 19 & $8.5 \times 10^{-2}$ & 0.10 & $0.50 \times 10^{-2}\left(0.20 \times 10^{-2}-1.0 \times 10^{-2}\right)$ & $4.2 \times 10^{-2}\left(2.6 \times 10^{-2}-7.0 \times 10^{-2}\right)$ \\
\hline All chronic data & 31 & $6.5 \times 10^{-2}$ & $8.5 \times 10^{-2}$ & $0.60 \times 10^{-2}\left(0.30 \times 10^{-2}-0.90 \times 10^{-2}\right)$ & $3.8 \times 10^{-2}\left(2.7 \times 10^{-2}-5.4 \times 10^{-2}\right)$ \\
\hline
\end{tabular}


Fig. 3 Species sensitivity distribution with the Potentially Affected Percentage versus pentachlorophenol concentrations for acute toxicity data (a) and chronic toxicity data (b)
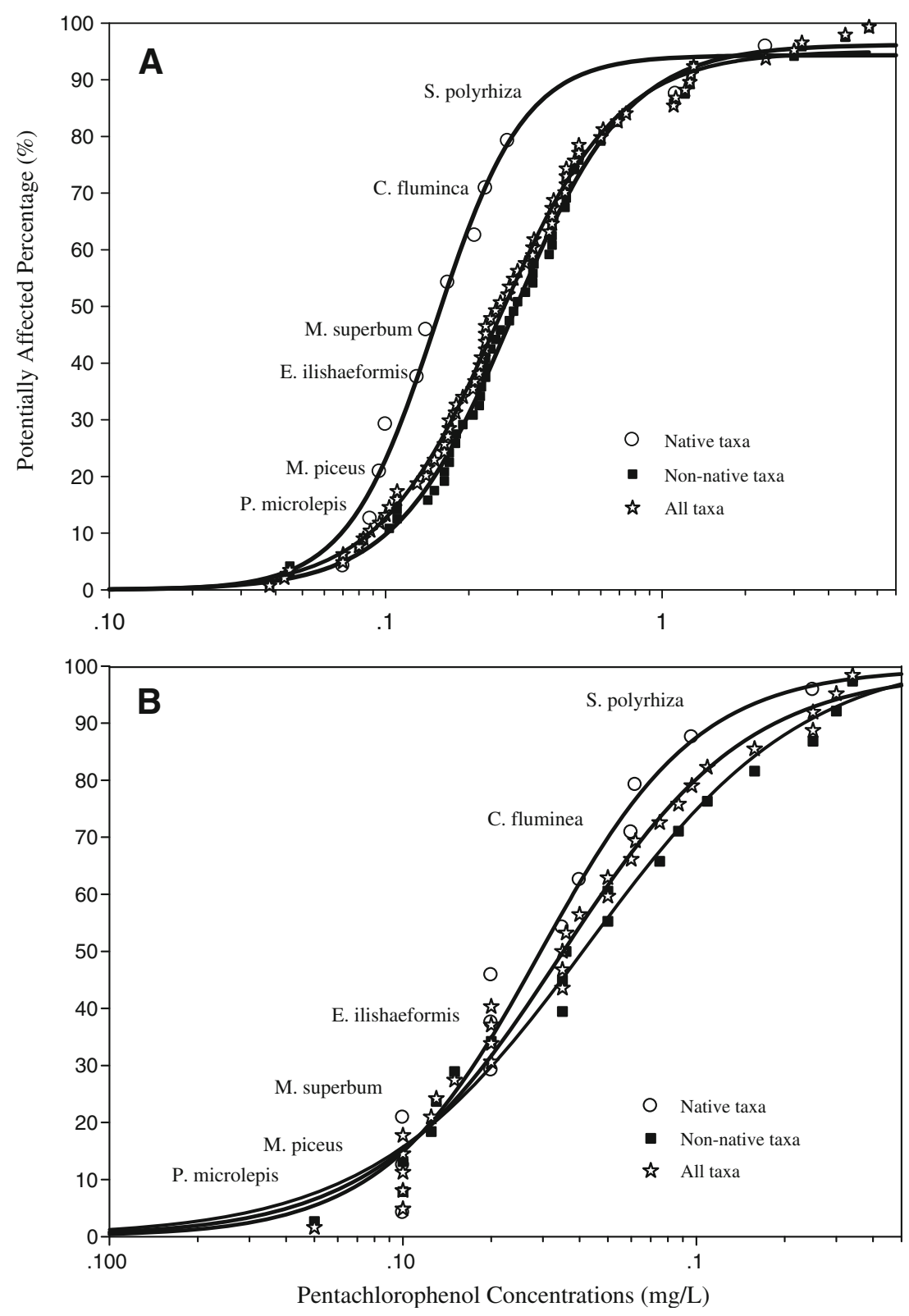

acute exposures to PCP were slightly more sensitive than the non-native species. However, while $\mathrm{HC}_{50}$ for native taxa was less than that for non-native taxa, the chronic toxicity of PCP, which is more critical for derivation of WQC, to endemic species were not significantly different between native and non-native taxa. The sensitivities of Australian and non-Australian organisms to endosulfan, based on calculate $\mathrm{HC}_{5}$ were similar (Hose and Van den Brink 2004). Similarly, sensitivities among North American and European taxa with different geographic distributions to a range of toxicants have been shown to be similar (Maltby et al. 2002; Dyer et al. 1997). Moreover, natural history, habitat type and geographical distribution of the species used to construct the SSD did not have a significant influence on the assessment of hazard, but taxonomic composition of the SSD does have a significant effect on their resulting estimates of the $\mathrm{HC}_{5}$ (Maltby et al. 2005).

Since $\mathrm{LC}_{50} \mathrm{~S}$ and NOECs for fishes are in the bottom portion of the SSD for PCP and those for invertebrates tend to be more in the middle of the $\mathrm{SSD}, \mathrm{HC}_{5} \mathrm{~S}$ are more influenced by toxicity of PCP to fishes. This explains why there is no obvious difference for $\mathrm{HC}_{5}$ derived from native species and those derived for non-native species. However for $\mathrm{HC}_{50} \mathrm{~s}$, the native invertebrate species are more sensitive to PCP, which results in a shift of the SSD to the left. Since in aquatic systems, some of the most and least sensitive species are small, and most aquatic organisms fall in the middle of the SSDs curves, the results of the statistical analyses indicate that conclusions based on $\mathrm{HC}_{50}$, might be different though those based on $\mathrm{HC}_{5}$ are similar. For this 
reason, in the Netherlands, both $\mathrm{HC}_{5}$ and $\mathrm{HC}_{50}$ are used to derive water quality standard (RIVM 2001).

Since the toxicity of PCP is dependent upon $\mathrm{pH}, \mathrm{HC}_{5}$ values and SSDs were evaluated for effects of $\mathrm{pH}$. Toxicity of PCP was pH-dependent and affected the SSDs for both native species and non-native species and derived $\mathrm{HC}_{5} \mathrm{~S}$ (see Table S1). The analysis was limited by the fact that toxicity data was available over a relatively limited range of $\mathrm{pH}$ values. The $\mathrm{pH}$ ranged from 7.4 to 7.8 for $87.5 \%$ of the toxicity data for native species, while. For $72.5 \%$ of the toxicity values for non-native species had an average $\mathrm{pH}$ of 7.79. The taxonomic composition of the species assemblage used to construct the SSD can have a significant influence on $\mathrm{HC}_{5}$ values (Hose and Van den Brink 2004; Maltby et al. 2005), but the small $\mathrm{pH}$ range over which most of the data were generated does not have a significant effect on the value of the $\mathrm{HC}_{5}$. For this reason and the fact that the $\mathrm{pH}$ range in most receiving environments in China is expected to be in the same range for which toxicity information used in the development of the SSD was generated the effect of species selected is far greater than the effect of $\mathrm{pH}$ is expected to be small. In the present study, there is no significant effect of the small $\mathrm{pH}$ range on the SSD derived from chronic data (see Fig. S1).

USEPA has recommended Criteria Maximum Concentration (CMC) and Criteria Continuous Concentration (CCC) of $19 \mu \mathrm{g} \mathrm{l}^{-1}$ (for $\mathrm{FAV}=38 \mu \mathrm{g} \mathrm{l}^{-1}, \mathrm{CMC}=\mathrm{FAV} \div 2$ ) and $15 \mu \mathrm{g} \mathrm{l}^{-1}$ at $\mathrm{pH} 7.8$ to protect freshwater organisms (USEPA 2006). Based on native species in China, the result showed a similar CMC (17.5 $\mu \mathrm{g} \mathrm{l}^{-1}, 35$ divided by 2$)$ but a smaller CCC $\left(6 \mu \mathrm{g} \mathrm{l}^{-1}\right)$. USEPA's CCC was derived using an acutechronic ratio that is smaller than indicated by the currently available chronic data, irrespective of international region. That is, the CCC difference does not appear to stem from sensitivity differences in native and non-native species.

\section{Conclusion}

The species endemic to China tested were slightly more sensitive than non-native species to the effects of PCP. However, based on statistical analyses of the SSDs, there were not statistically significantly differences in sensitivities between the native and non-native species. Therefore, water quality criteria for PCP derived from native species were numerically less than those deriving from non-native species, but in the same order of magnitude. Species representative of regional populations could be used to develop site-specific WQC for PCP, but the results would not be significantly different than values derived from SSDs based on non-native species. Thus, it can be concluded that there is no reason to develop WQC for PCP that are based on species endemic to China. This is likely due to the fact that PCP is a non-specific respiratory inhibitor and the biochemical mechanisms of the systems affected by PCP are conserved among species.

Acknowledgements This research was financially supported by National Natural Science Foundation of China (40703025), National High-Tech R\&D Program of China (2007AA06A405), and National S\&T Major Project of China (2008ZX07211-007). Prof. Giesy was supported by the Canada Research Chair program, an at large Chair Professorship at the Department of Biology and Chemistry and State Key Laboratory in Marine Pollution, City University of Hong Kong, The Einstein Professor Program of the Chinese Academy of Sciences and the Visiting Professor Program of King Saud University. We also thank Dr. Charles G. Delos from the Office of Water, U.S. Environmental Protection Agency, Washington, DC, for the assistance with manuscript and valuable comments.

\section{References}

Adema DMM, Vink IGJ (1981) A comparative-study of the toxicity of 1,1,2-trichloroethane, dieldrin, pentachlorophenol and 3,4 dichloroaniline for marine and fresh-water organisms. Chemosphere 10:533-554

ANZECC \& ARMCANZ (2000) Australian and New Zealand guidelines for fresh and marine water quality. Australian and New Zealand Environment and Conservation Council and Agriculture and Resource management Council of Australia and New Zealand, Canberra, Australia

ASTM (1993) Standard guide for conducting acute toxicity tests with fishes, macroinvertebrates and amphibians. Annual book of ASTM standards. American Society of Testing and Materials, Philadelphia, PA, USA, pp 88-729

Belgers JDM, Aalderink GH, Van den Brink PJ (2009) Effects of four fungicides on nine non-target submersed macrophytes. Ecotoxicol Environ Saf 72:579-584

Besser JM, Wang N, Dwyer FJ, Mayer FL, Ingersoll CG (2005) Assessing contaminant sensitivity of endangered and threatened aquatic species: Part II. Chronic toxicity of copper and pentachlorophenol to two endangered species and two surrogate species. Arch Environ Contam Toxicol 48:155-165

Caldwell DJ, Mastrocco F, Hutchinson TH, Lange R, Heijerick D, Janssen $C$ et al (2008) Derivation of an aquatic predicted noeffect concentration for the synthetic hormone, 17 alpha-ethinyl estradiol. Environ Sci Technol 42:7046-7054

Campbell E, Palmer MJ, Shao Q, Warne MSJ, Wilson D (2000) BurrliOZ: a computer program for calculating toxicant trigger values for the ANZECC and ARMCANZ water quality guidelines. Perth, Western Australia

Crossland NO (1985) A method to evaluate effects of toxic chemicals on fish growth. Chemosphere 14:1855-1870

Davies PE, Cook LSJ, Goenarso D (1994) Sublethal responses to pesticides of several species of Australian fresh-water fish and crustaceans and rainbow-trout. Environ Toxicol Chem 13:13411354

Duboudin C, Ciffroy P, Magaud H (2004) Acute-to-chronic species sensitivity distribution extrapolation. Environ Toxicol Chem 23:1774-1785

Dwyer FJ, Mayer FL, Sappington LC, Buckler DR, Bridges CM, Greer IE et al (2005) Assessing contaminant sensitivity of endangered and threatened aquatic species: Part I. Acute toxicity of five chemicals. Arch Environ Contam Toxicol 48:143-154

Dyer SD, Belanger SE, Carr GJ (1997) An initial evaluation of the use of Euro/North American fish species for tropical effects assessments. Chemosphere 35:2767-2781 
Dyer SD, Versteeg DJ, Belanger SE, Chaney JG, Raimondo S, Barron MG (2008) Comparison of species sensitivity distributions derived from interspecies correlation models to distributions used to derive water quality criteria. Environ Sci Technol 42:3076-3083

Gao JJ, Liu LH, Liu XR, Zhou HD, Huang SB, Wang ZJ (2008) Levels and spatial distribution of chlorophenols 2,4-dichlorophenol, 2,4,6trichlorophenol, and pentachlorophenol in surface water of China. Chemosphere 71:1181-1187

Ge JC, Pan JL, Fel ZL, Wu GH, Giesy JP (2007) Concentrations of pentachlorophenol (PCP) in fish and shrimp in Jiangsu Province, China. Chemosphere 69:164-169

Giddings JM, Barber I, Warren-Hicks W (2009) Comparative aquatic toxicity of the pyrethroid insecticide lambda-cyhalothrin and its resolved isomer gamma-cyhalothrin. Ecotoxicology 18:239-249

Giesy JP, Solomon KR, Coats JR, Dixon KR, Giddings JM, Kenega EK (1999) Ecological risk assessment of chlorpyrifos in North American aquatic environments. Rev Environ Contam Toxicol 160:1-129

Grist EPM, O'Hagan A, Crane M, Sorokin N, Sims I, Whitehouse P (2006) Bayesian and time-independent species sensitivity distributions for risk assessment of chemicals. Environ Sci Technol 40:395-401

Hickey CW, Martin ML (1995) Relative sensitivity of five benthic invertebrate species to reference toxicants and resin-acid contaminated sediments. Environ Toxicol Chem 14:1401-1409

Hose GC, Van den Brink PJ (2004) Confirming the species-sensitivity distribution concept for endosulfan using laboratory, mesocosm, and field data. Arch Environ Contam Toxicol 47:511-520

Jagoe RH, Newman MC (1997) Bootstrap estimation of community NOEC values. Ecotoxicology 6:293-306

Klimisch HJ, Andreae M, Tillmann U (1997) A systematic approach for evaluating the quality of experimental toxicological and ecotoxicological data. Regul Toxicol Pharm 25:1-5

Mallett MJ, Grandy NJ, Lacey RF (1997) Interlaboratory comparison of a method to evaluate the effects of chemicals on fish growth. Environ Toxicol Chem 16:528-533

Maltby L, Blake N, Brock TCM, Van den Brink PJ (2002) Addressing interspecific variation in sensitivity and the potential to reduce this source of uncertainty in ecotoxicological assessments. DEFRA project code PN0932. UK Department for Environment, Food and Rural Affairs, London, UK

Maltby L, Blake N, Brock TCM, Van Den Brink PJ (2005) Insecticide species sensitivity distributions: importance of test species selection and relevance to aquatic ecosystems. Environ Toxicol Chem 24:379-388

Nie JL, Liu F, Zhou CY, Liu ZT (2001) Study on the acute and subacute toxicities of chlorophenols on Carassias auratus. Res Environ Sci 14:6-8 (in Chinese)

OECD (2002) OECD Guidelines for the testing of chemicals, revised proposal for a new guideline 221, Lemna sp. growth inhibition test. OECD, Paris, France

Orton F, Lutz I, Kloas W, Routledge EJ (2009) Endocrine disrupting effects of herbicides and pentachlorophenol: in vitro and in vivo evidence. Environ Sci Technol 43:2144-2150

RIVM (2001) Guidance document on deriving environmental risk limits in The Netherlands.Report no.601501012. In Traas TP (ed) National Institute of Public Health and the Environment, Bilthoven, The Netherlands

Roessink I, Belgers JDM, Crum SJH, van den Brink PJ, Brock TCM (2006) Impact of triphenyltin acetate in microcosms simulating floodplain lakes: II. Comparison of species sensitivity distributions between laboratory and semi-field. Ecotoxicology 15:411-424

Shao Q (2000) Estimation for hazardous concentrations based on NOEC toxicity data: an alternative approach. Environmetrics 11(5):583-595

Simpson SL (2005) Exposure-effect model for calculating copper effect concentrations in Sediments with varying copper binding properties: a synthesis. Environ Sci Technol 39:7089-7096
Solomon KR, Giesy JP, Jones PD (2000) Probabilistic risk assessment of agrochemicals in the environment. Crop Protect 19:649-655

Song ZH, Huang GL (2005) Toxic effects of pentachlorophenol on Lemna minor. B Environ Contam Toxicol 74:1166-1172

Song ZH, Huang GL (2007) Toxic effects of pentachlorophenol on Lemna polyrhiza. Ecotoxicol Environ Saf 66:343-347

Stangroom SJ, Collins CD, Lester JN (1998) Sources of organic micropollutants to lowland rivers. Environ Technol 19:643-666

Thakur IS, Verma PK, Upadhaya KC (2001) Involvement of plasmid in degradation of pentachlorophenol by Pseudomonas sp from a chemostat. Biochem Biophys Res Commun 286:109-113

USEPA (1985) Guidelines for deriving numerical national water quality criteria for the protection of aquatic organisms and their uses. National Technical Information Service Accession Number PB85-227049. United States Environmental Protection Agency. Washington, DC, USA

USEPA (1986) Ambient water quality criteria for pentachlorophenol. United States Environmental Protection Agency, Washington, DC, USA

USEPA (1990) Dunett Program Version 1.5, Probit Program Version 1.5, and Trimmed spearman-Karber (TSK) Program Version 1.5, Ecological Monitoring Research Division. Environmental Monitoring Systems Laboratory, United States Environmental Protection Agency, Cincinnati, OH, USA

USEPA (1991) Water Quality Criteria Summary, Ecological Risk Assessment Branch (WH-585) and Human Risk Assessment Branch (WH-550D). In: Health and Ecological Criteria Division U (ed). Washington, DC, USA

USEPA (1993) Methods for measuring the acute toxicity of effluents and receiving waters to freshwater and marine organisms. United States Environmental Protection Agency. Cincinnati, OH, USA

USEPA (2002) U.S. Environmental Protection Agency, ECOTOX Database; U.S. EPA, Washington, DC. Available at http://cfpub. epa.gov/ecotox/

USEPA (2006) National Recommended Water Quality Criteria, United States Environmental Protection Agency, Washington, DC, USA

Vanstraalen NM, Denneman CAJ (1989) Ecotoxicological evaluation of soil quality criteria. Ecotox Environ Saf 18:241-251

Verma SR, Rani S, Tyagi AK, Dalela RC (1980) Evaluation of acute toxicity of phenol and its chloro-derivatives and nitro-derivatives to certain teleosts. Water Air Soil Pollut 14:95-102

Wheeler JR, Grist EPM, Leung KMY, Morritt D, Crane M (2002) Species sensitivity distributions: data and model choice. Mar Pollut Bull 45:192-202

Xia Q, Chen YQ, Liu XB (2004) Water quality criteria and standards. Standard Press in China, Beijing (in Chinese)

Yin DQ, Hu SQ, Jin HJ, Yu LW (2003a) Deriving freshwater quality criteria for 2,4,6-trichlorophenol for protection of aquatic life in China. Chemosphere 52:67-73

Yin DQ, Jin HJ, Yu LW, Hu SQ (2003b) Deriving freshwater quality criteria for 2,4-dichlorophenol for protection of aquatic life in China. Environ Pollut 122:217-222

Yuan XH, Yang ZH (1983) Botanic physiological and biochemical test. Advanced Education Publishing Company, Beijing (in Chinese)

Zha JM, Wang ZJ, Schlenk D (2006) Effects of pentachlorophenol on the reproduction of Japanese medaka (Oryzias latipes). Chem-Biol Interact 161:26-36

Zhang T, Jin HJ (1997) Use of duckweed (Lemna minor L.) growth inhibition test to evaluate the toxicity of acrylonitrile, sulphocyanic sodium and acetonitrile in China. Environ Pollut 98:143-147

Zheng MH, Zhang B, Bao ZC, Yang H, Xu XB (2000) Analysis of pentachlorophenol from water, sediments, and fish bile of Dongting lake in China. B Environ Contam Tox 64:16-19

Zhou YX, Cheng SP, Hu W (1995) The Gobiocypris rarus seven-day subchronic toxicity test. Acta Sci Circumstantiae 15:375-380 (in Chinese) 